\title{
Overambition as Disability: Discrimination of Excellence
}

\author{
Julia M. Puaschunder ${ }^{1,2}$ \\ ${ }^{1}$ The New School, Parsons School of Design, Department of Economics, 6 East $16^{\text {th }}$ Street, $9^{\text {rd }}$ floor 89, New York, \\ NY 10003,USA, Julia.Puaschunder@newschool.edu, T 001212229 5700,F 0012122295724, \\ www.juliampuaschunder.com \\ ${ }^{2}$ Columbia University, Graduate School of Arts and Sciences, Julia.Puaschunder@columbia.edu, \\ http://blogs.cuit.columbia.edu/jmp2265
}

\begin{abstract}
This paper draws attention to discrimination of excellence in order to propose an inequality alleviation strategy in connecting overachievers with discriminated-against minorities. Discrimination of excellence is the unjust treatment of outperformers and overachievers. Defining discrimination of excellence and describing the implicit mechanisms of aversion against excellence depicts overambition as handicap. Overambition may thereby become a disability. This article first introduces the concept of discrimination of excellence, to then draw inferences about overachievement being comparable to a disability. Lastly, discrimination of excellence alleviation strategies are proposed.
\end{abstract}

KEYWORDS: Aversion against excellence, Disability, Discrimination of excellence, Inequality, Justice, Outperformance, Overambition

\section{Introduction}

Discrimination of excellence is the unjust treatment of outperformers and overachievers or followers that have the potential to one day become better than leaders. Discrimination against outperformers includes the critique of unfair treatment in non-merit-based admissions practices, degree conferral or promotion standards. Unfair treatment of outperformers occurs when focusing away from merit or biases lead to economic inefficiency or suboptimal choice in the wake of intransparent, arbitrary or nepotistic decision-making. Discrimination against excellent students during admissions is thematized in Ivy League admission debates and legally scrutinized in the context of individuals outperforming on standardized college admission tests but not being admitted. Discrimination of excellence evidence is found in most outstanding students failing a $\mathrm{PhD}$ degree conferral and intransparent promotion criteria systemically biasing against outperformers and overachievers (Puaschunder 2019a, b).

\section{Theory}

Discrimination is unjust or prejudicial treatment of different categories of people or things. Attempts exist to legally abolish, economically counter-weight and societally alleviate the negative consequences of discrimination around the world. The Fifth and Fourteenth Amendments to the United States Constitution ban the federal and state governments from discriminating. The United States Employment Discrimination laws seek to prevent discrimination based on race, sex, sexual orientation, religion, national origin, physical disability, and age by employers. The United States Equal Employment Opportunity Commission lists as especially sensitive areas of discrimination attention age, disability, equal pay and compensation, genetic information, harassment, national origin, pregnancy, race and color, religion, retaliation, sex and sexual harassment. The European Union introduced an Anti-Discrimination Directive to ban discrimination on the grounds of age, disability, religion or belief and sexual orientation. The Lisbon Treaty on European Union and the Treaty on the Functioning of the European Union serves as legal protection against discrimination acknowledging equal rights for all human to be treated unbiased and with equal fairness and dignity. 
Discrimination of excellence includes the 2019 college admission fraud scandals, standardized admission test outperformers suing a U.S. higher education institution and the United States Department of Justice scrutinizing higher education over potential systemic biases in college admission standards that would underweight transparent standardized testing criteria. University and college admission and promotion criteria are critical career gatekeeping events, in which unexpectedly overweighting intransparent, non-merit based criteria can result in meritbased outperformers underperforming in admissions. Discrimination bias can occur in meritbased up-or-out placement and promotion criteria in hierarchical rank orders, when performance is partially measured on intangible or intransparent performance criteria implying potential economic inefficiency.

Economic foundations: Outperformance is the foundation of excellence. Overachievement is related to investments. Outperformance and overachievement are bases of the intellectual elites and related to luxury consumption. Overachievement instigates economic growth. John Maynard Keynes' multiplier effect attributes investments of overachievers as drivers of economic growth. Investments of the striving elite multiply in economic spending in the overall economy. Too-big-to-fail bailout and leadership arguments back the idea of bundling excellence in elites, whose larger-scaled overachiever projects are funded by long-term investments that stimulate economic growth.

Consumption of the elite is an economic growth factor. Thorstein Veblen's trickling down of excellence emphasizes that luxury consumption is a driver of economic growth and accelerator of social enhancement and cultural advancement. Conspicuous consumption motivates others to strive to consume as well and be economically productive to achieve this goal. The American Dream ideals of striving to outperform are foundations of economic productivity. Economic inefficiencies of discrimination of excellence range from lost economic potential and inefficiencies, career-switching costs and diminishing human capital and labor productivity. Health and societal risks experienced in the wake of discrimination imply social, sociopsychological and emotional burdens (Puaschunder 2020).

Historical foundations: Slowing down overachievers and abolishing intellectual outperformance has occurred throughout history. After the Taj Mahal was built, rumor has it, all workers' hands were amputated and the architects disappeared - allegedly, to avoid a second palace to ever be created like the Taj Mahal. Various regimes attempted to eradicate, cut down or slow performance and discourage individual striving - e.g., Cambodia, Holocaust, genocides targeting intellectual groups.

Societal structure: Discrimination of excellence theory integrates the 'übergroup' in the social psychology social identity theory categorization of society into so-called 'ingroups' and 'outgroups.' 'Übergroups' capture the societal position of natural strivers who outperform and therefore are prone to face discrimination of excellence. Socio-demographic prevalences include age groups, hierarchical positions and seniority principles that may breed discrimination of excellence.

Social-psychological motives: Socio-psychological motives and emotions that cause and accompany discrimination of excellence include envy, jealousy, inferiority complex, reputation greed and suboptimal group norms.

The problems around overachievement can also be addressed as a disability. A disability is any condition that makes it more difficult for a person to do certain activities or interact with the world around them. These conditions, or impairments, may be of cognitive nature and in combination with environmental factors. The overachievement of an individual may lead to an unfavorable or hostile environment, in which impairments occur. Disabilities is an umbrella term, covering impairments, activity limitations, and participation restrictions. An impairment is a problem and an activity limitation is a difficulty encountered by an individual in executing a task or action; while a participation restriction is a problem experienced by an individual in involvement in life situations. Disability is thus not just a health problem. It is a complex 
phenomenon, reflecting the interaction between features of a person's body and features of the society in which he or she lives (World Health Organization 2020). Stereotypes, associated with either disability in general, or with specific disabilities serve as a justification for ableist practices and reinforce discriminatory attitudes and behaviors toward people who are disabled. Labeling affects people when it limits their options for action or changes their identity. In ableist societies, people with disabilities are viewed as less valuable, or even seen as a weird person. The eugenics movement of the early 20 th century would be considered an example of widespread ableism.

Interpreting overachievement as disability refer to limitations imposed on people by the constraints of an ableist society that reacts to overachievement with prejudice. On this basis, people are unfairly assigned perceived abilities and character orientations. Based on inaccurate attributions and implicit emotional fallouts of their environment, overachievers may be denied certain rights and privileges. Overachievement or giftedness can be defined as a disability because it will frequently create difficulties for individuals to function in society as a "normal" person. From a young age, overachievers are harassed and discriminated against by their peers, put into an outcast position, and labelled as "nerds", "geeks", or "weirdo." Consequently, gifted children often develop social inhibitions and traumas that they are not able to shed, if ever, well into adulthood. While overachievers frequently have abilities that allow them to succeed academically and thus leave their peers behind, their social deficits are often a counterweight that balance or outweigh their advantages, thus ultimately resulting in a lower degree of life success. Overachievers consequently often struggle with professional success, and they have difficulty in their social life, for example forming meaningful relationships with the others.

\section{Empirics}

While theoretical presenting a preliminary idea of an economic model of value transfer between equality and inequality, my subsequent research will target at finding inequality alleviation strategies. Qualitative and quantitative empirical data on direct and indirect transactions and interaction outcomes between equality and inequality representing agents within societal networks will be retrieved on the following multiple domains. Further, a field experiment and applicability check in real-world settings are endeavored to be pursued.

\section{Discussion}

After a theoretical foundation of Discrimination of Excellence and introduction of strivers as uebergroups in society, future research should empirically focus on qualitative case studies, diary technique collected data and an external review report in the higher education sector vividly outline discrimination based on excellence. Qualitative analyses of $\mathrm{PhD}$ studies blog entries reveal a pattern of outperformers being forced out of higher educational institutions to successfully continuing in higher-ranked institutions. Evidence of intangible admission criteria, unfair testing situations and delayed or unsuccessful academic promotion statistics serve as additional evidence on discrimination against excellence. Resistance to share information on testing and promotion criteria transparently are detected to allow for discrimination. Macro-economic analyses reveal industries that are prone to breed discrimination based on excellence to estimate the short- and long-term losses of discrimination of excellence based on economic trickling down and too-big-to-fail arguments but also Keynes' multiplier innovatively applied in endogenous growth theory alongside including health and societal risks in the wake of discrimination. Macro-economic cross-sectional and time series analyses in the laboratory of modern world history outline socio-economic costs of slowing outperformers and abolishing intellectual advancement. Artificial intelligence increasing the currently unprecedentedly wide divide between skilled and unskilled labor is predicted to even higher importance of attention to excellence in the future. 
Alleviation strategies: Excellence is an asset of the economy and society. Protection from discrimination is grounded in human beings being treated with equal respect and dignity. Respect for excellence offers individual well-being derived from dignity, economic prosperity grounded in large-scale individuals' striving and societal advancement founded on overachieving elites.

Legal codifications, economic action and public policy as well as corporate workplace incentives protect performance free from discrimination. Awareness building, transparency and mandatory access to information on hiring, testing and promotion criteria appear as natural remedies besides legal action to combat discriminating individuals, institutional and systemic structures.

Cultures-of-excellence safe havens but also rescue funds for those whose career has taken a hit due to discrimination of excellence are discrimination alleviation strategies. In order to overcome a performance polarization between uebergroups and outgroups, uebergroups can transfer performance strategies to potentially underperforming outgroups, who can offer in lieu knowledge on discrimination coping strategies. The strategic alliance of out- and underperformers offers a more productive and anti-discrimination-sensitive workplace, economy, democracy and society.

Thomas Piketty's (2014) Capital in the 21st Century revolutionized economic thoughts on inequality. Started by the 2008/09 World Financial Crisis and thematized in the subsequent Occupy movement but also revitalized in the post-COVID-lockdown period, attention to rising inequality regarding wage, opportunity and wealth led to advocacy for a more equal society. Puaschunder (2016) modelled economic wealth transfer in dyads of exchange between crystallized value based on heritage (e.g., royal families, legacy admits) and merit-based equality represented by outperforming offspring from families with underprivileged backgrounds. Puaschunder's (2016) theoretical economic model argues for beneficial economic outcomes if social capital holding legacy admits connect with outperforming ambitious strivers of underprivileged backgrounds at higher education institutions. On the societal level, within networks favorable environments may serve as transformation hubs if connecting social capital with merit-based underprivileged outperformers. Overall, this research strives to grant hope in Piketty's outlook of rising inequality by showing the economic merits of inequality when paying attention to value transfer opportunities, in which social capital of legacy admits is exchanged for excellence strategies of merit-based outperformers.

Overall, future research may focus on finding legal codifications, economic action and public policy as well as corporate workplace incentives to protect performance free from discrimination. Awareness building, transparency and mandatory access to information on hiring, testing and promotion criteria appear as natural remedies besides legal action to combat discriminating individuals, institutional and systemic structures. Cultures-of-excellence safe havens but also rescue funds for those whose career has taken a hit due to discrimination of excellence are loss alleviation strategies. In order to overcome an educational inequality and performance polarization between outperforming uebergroups and outgroups, uebergroups can transfer performance strategies to potentially underperforming outgroups, who can offer in lieu knowledge on discrimination coping strategies.

In the end, this research will celebrate outperformers as asset of the economy and protection of excellence a source of dignity and sophistication of society. As a most innovative extension on the knowledge of excellence, the research will also address the socio-economic value of luxury in its purest form representing a Gestalt that is more excellent than the sum of its pieces, a unique mastery over the world that serves a common purpose. Protection from discrimination ensures human beings being treated with equal respect and dignity. Respect for excellence offers individual well-being derived from dignity, economic prosperity grounded in large-scale individuals' striving and societal advancement founded on overachieving elites. The strategic alliance of out- and underperformers offers the vision of a more productive and antidiscrimination-sensitive workplace, economy, democracy and society. 


\section{References}

Puaschunder, Julia Margarete. 2016. "The beauty of ivy: When inequality meets equality." Global Journal of Management and Business Research: Economics and Commerce 16 (3): 1-11.

Puaschunder, Julia Margarete. 2019a. Discrimination of excellence. Copyright Office of the United States Congress. TXu002167333 / 2019-10-08.

Julia Margarete Puaschunder. 2019b. "Discrimination of excellence: A research agenda." Proceedings of the 14th International Research Association for Interdisciplinary Studies (RAIS) conference at the Erdman Center of Princeton University, pp. 54-58, Princeton, New Jersey, USA, August 19-21.

Puaschunder, Julia Margarete. 2020. "Review of the making marvels: Exhibit at the Metropolitan Museum of Art." New York, New York. Luxury: History, Culture, Consumption 5 (3): 265-280.

World Health Organization. "Disabilities." Retrieved online at https://www.who.int/healthtopics/disability\#tab=tab_1. 